\title{
Structural \& Thermal Analysis of the Dental Refurbishment Ingredients using FEA Application
}

\author{
Ajay Agrawal
}

\begin{abstract}
Very little scientific information on dental renewables has recently been available. Before this experience, the utilization of these materials was entirely artistic, and the patient's mouth was the only testing laboratory. Today, despite the advanced technical devices and the improvement of consistent test methods for estimating the metallic and thermal properties of renewables, this test sometimes happens on the patient's mouth. The current work has considered, and compared, basic thermal \& mechanical characteristic's of some of the most commonly used restorative materials. The transport of these materials when they were used as a class I cup, mandibular $1^{\text {st }}$ molar, was mixed under different thermal and structural strengths examining the use of ANSYS/work bench 15.0. Consideration was given to Amalgam materials, Composite/mixture, \& gold alloy for this effort. The outcomes obtained from ANSYS indicated that the biggest update at the occlusal surface, particularly in the inflection, occurred and is rising to the other four (mesial, \& buccal, \& lingual \& distal surfaces) characteristics \& the roots, though Von-Mises was depicted on the cervical line/mark (a border between crown and roots) and spread to both crown \& roots. There were 35 tests carried out and the values for the highest separation and von-Mises emphasis both against temperature and structure by using QTIPLOT software, and the final result shows that all values are the highest and highest concentrations of both re-fillers of gold and the mixed nutrients and of both deformation \& von-Mises stresses respectively.
\end{abstract}

Keywords - cavity, dental renewable, ANSYS, Amalgam material, (Von-Mises) stress.

\section{INTRODUCTION}

The key aims of dentistry are to maintain or progress/increase the quality of life of dental patients. These aims can be achieved by preventing disease, relieving pain, developing resilience, developing speech and enhancing appearance.

As many of these objectives require renewal or modification of tooth structure, they are the main challenge for centuries in the development and selection of biocompatible, long-lasting, direct filling tooth restorative and prosthetic recyclable, double-ended material. May face up to poor conditions in oral surroundings.

Despite the body of domestic and international professionals managing the public, many people struggled to forget their normal health use on their teeth. As a result, the part of teeth still linked to teeth can have germs caused by a number of dental difficulties. For instance, Tooth cavity (" $a$ little hole which is formed when a sticky bacteria, called plaque, builds up on the teeth, slowly destroying the hard outer shell")a pulse hole is when the bacterial bacteria

Revised Manuscript Received on August 05, 2019.

Ajay Agrawal, Department of Mechanical Engineering, Sanskriti University, Uttar Pradesh,India. (E-mail: sanpubip@gmail.com) called a plaque grow on teeth, \& slowly destroy the outer solid shell, one of these diseases.

To treat the dentist's ability to remove the worn out fragment of the tooth $\&$ then "enter" the area on the tooth where the material has been removed. Folds are also employed to patch-up teeth and broken teeth which have been reduced from misuse (for example, by poisoning or tooth decay) [1] [2], [3].

\section{MATERIALS AND METHOD}

Having carried out numerous studies of the available literatures and different professional professions, mandibular first molar, which are considering the highest of the booming force, were selected. Additionally, the early molar whistle may be considered the most important tooth, due to the early explosion; it may need to rebuild over any other tooth [4], [5]. "Usually, a mandibular first molar has five well-developed cusps: two buccal, two lingual, and one distal cusp. It has also two buccolingually broad roots, one in mesial and one in distal side, which are widely separated at the apices" [6] [7]. A classic cross-section of tooth structure is presented in the Figure 1 below:

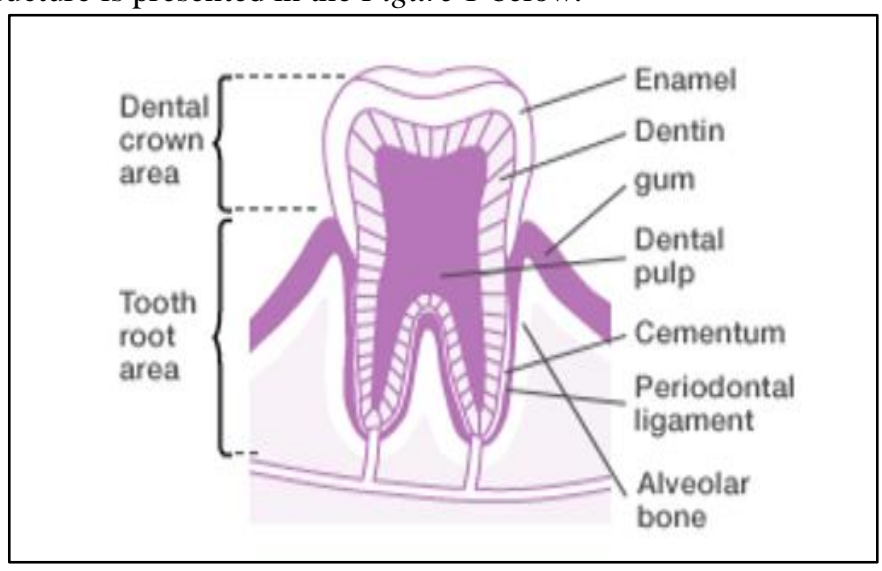

Figure 1. Structure of tooth

\section{SOFTWARE APPROACH}

Clinical dentistry is a great responsibility that the teeth are not renewed. After receiving several dental treatments, the teeth may have left as outcome of some exceptional nonconfident situations.

This has cheered roughly few researchers/scholars to examine the mechanical \& thermal reaction of teeth after several dental conducts/cures that are acknowledged as source cause of dentistry failure. Experience in this area is 
therefore essential for stress and thermal/temperature distribution. Furthermore, the direct measurement of stress \& temperature circulations across the buccal, \& mesial, \& lingual, \& distal \& occlusal tooth surfaces is largely impossible because they cannot gain access to it.

A method known for determining the stress and temperature distribution within a multifaceted structure is finite element method/technique (FEM). The FEM was tested to produce results similar to other test procedures like photo-elastic examinations and stress measurement. However, the integrity of the photo-elastic tissue is more comprehensive, and measurements are not restricted, as it is not limited to a fixture position. In circumstance, the FEM delivers more thorough \& smoother mechanical responses [5] [8] [9].

\section{CREATING 3D MODEL OF GEOMETRY}

In general, a tooth geometry has a complex shape; creating the right and true shape of the model is tired and time consuming. So an estimating module can be created using the available technologies and the method of Reverse Engineering. The collected tooth for clinical tenacities was scanned using the Tomography Computing (CT) scanning tool. The scanning happens in various heights at various angles to generate a more accurate format. The scanned image/figure was found as .DICOM file transforming to 3-D model. It may also likely to produce the 3 -D model/module employing a white light/ray scanner. But the correct result is creating the shape of CT scan tool, because score data of the buttons appears as dots that are less clear of the DICOM file obtained, since the CT scan [10], [11].

Saving file as .SLDPRT has been released/open with Solid Works application/software \& a model class I cavity has been made. On the surface, there are numerous diverse kinds of lump. Regardless of what size or shape, when a cavity is made on the surface of occlusal, it is called class I cavity, [12]. Filling material was then created to fill the created cuckoo. The rounded up model saved and represented in Figure 2.

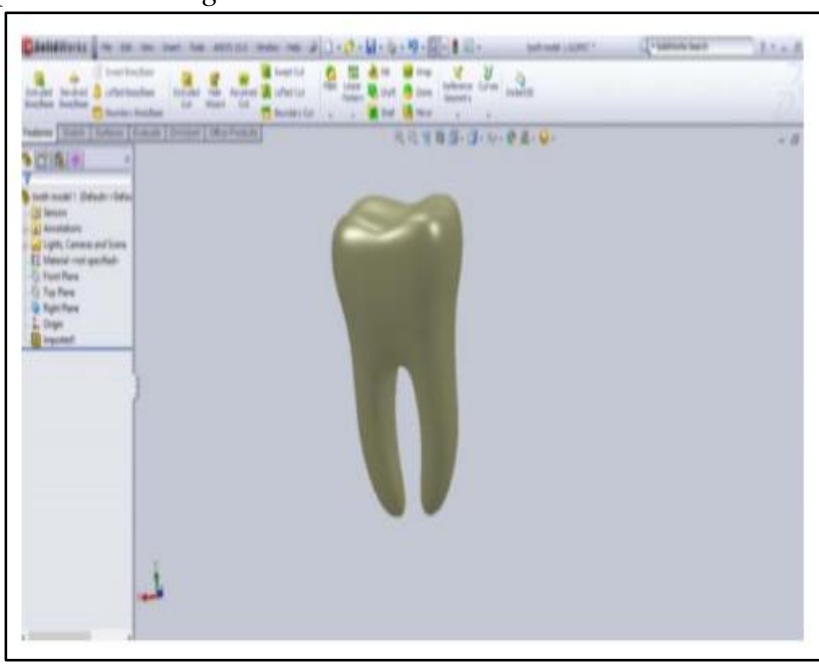

Figure 2. 3D model of the geometry

IGES was introduced to the ANSYS application for analysis. The model was impaired by the help of a slightly reduced size for a better result and the properties specified. A typical tooth structure comprises of an enamel, \& dentin, $\&$ cementum \& pulp tissue, as displayed in Figure 1 above.
The percentage of tooth, which is open to the sun's talk is known as the dental crown, \& the part under the crown of the dentist is known as the root of the teeth [7]. Consideration was given to dissimilar blends of the temperature and structural types chosen, and the model was set to limit mineral boundaries.

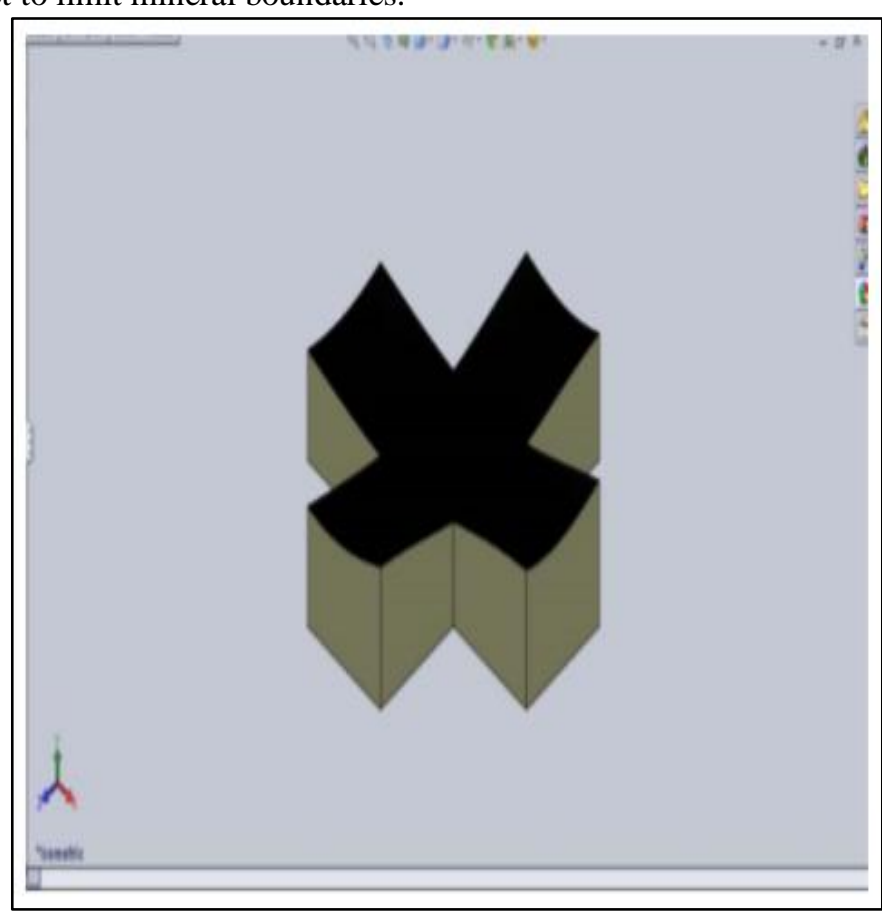

Figure 3. Equipped filling material

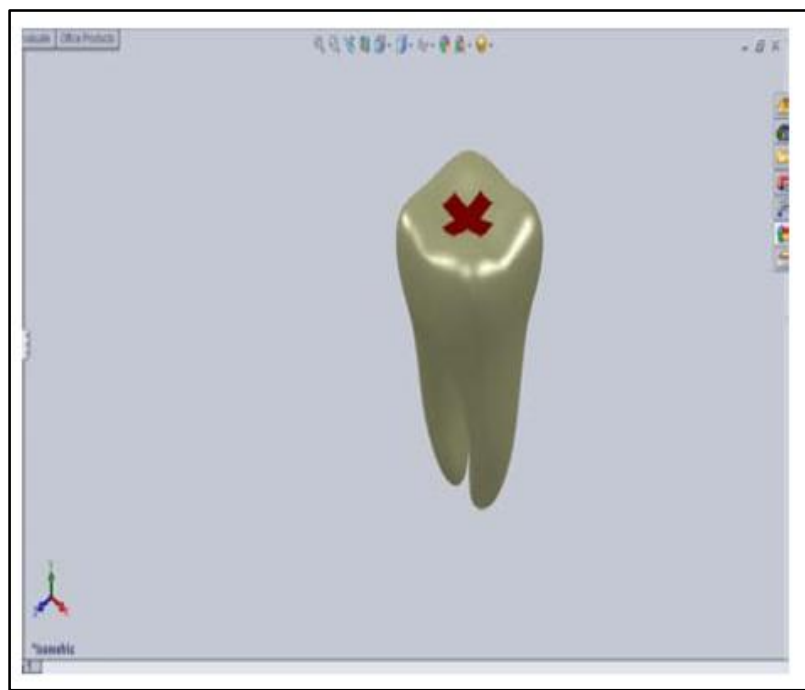

Figure 4. Model/module occupied with material

\section{STRATEGY/DESIGN OF EXPERIMENTATION}

3 materials (Amalgam, \& Composites, \& Gold alloy) were selected. For each material, a mixture/combination of structural and heating/thermal was considered. The largest force decreases from the molar with the incisor part, and the mean average on the $1^{\text {st }} \& 2^{\text {nd }}$ biting force is about $580 \mathrm{~N}$ [13]. Prior to this experience, four forces of excellence, one above and three below, were selected. Only a small/little 
quantity of published research has been obtained to allow the range of oral temperatures that come between the hard and soft cells, but the temperature that may be adjusted in the performance of dental ingredients could be inside oral surroundings. "The highest and lowest temperature recorded shows that hot fluid can raise the intense temperature of the teeth to about 70 degrees Celsius and the consumption of iced drinks lowers the same teeth to around 0 degrees Celsius" [14], [15]. For this reason, four temperatures range from a scale of $0^{\circ} \mathrm{C}$ to $60^{\circ} \mathrm{C}$ at an interval of $20^{\circ} \mathrm{C}$ selected. So; 48 numbers of tests should be run entirely (i.e. 3 materials, 4 structural forces and 4 temperatures).

\section{RESULTS}

For each/every combination of thermal \& structural evaluation, the problem was solved and the resulting mechanical response was recorded. Few outcomes are presented in diagram below:

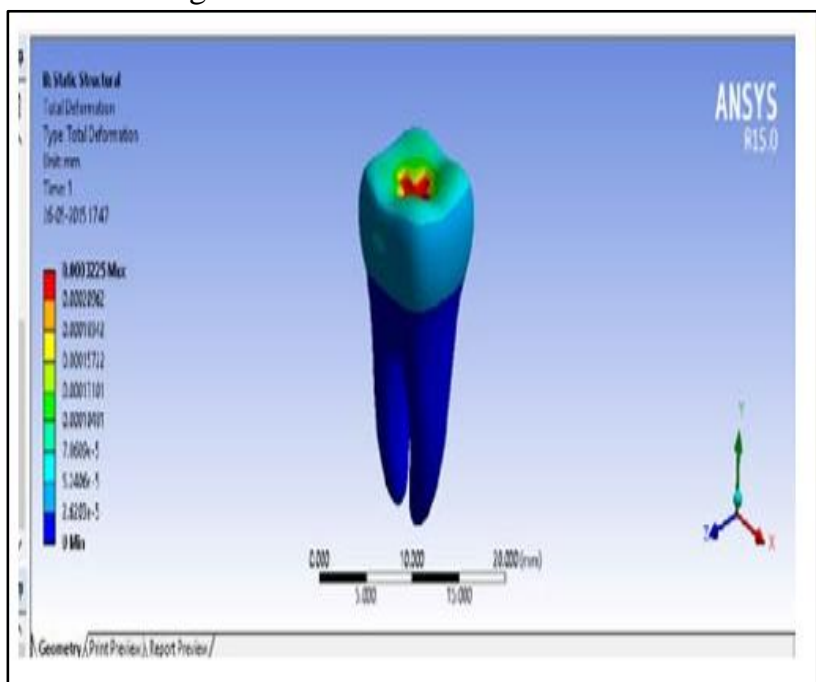

Figure 5. Distortion examination for Amalgam at $0^{0} \mathrm{C}$ \& 80N

Max distortion; $0.0003233 \mathrm{~mm}$

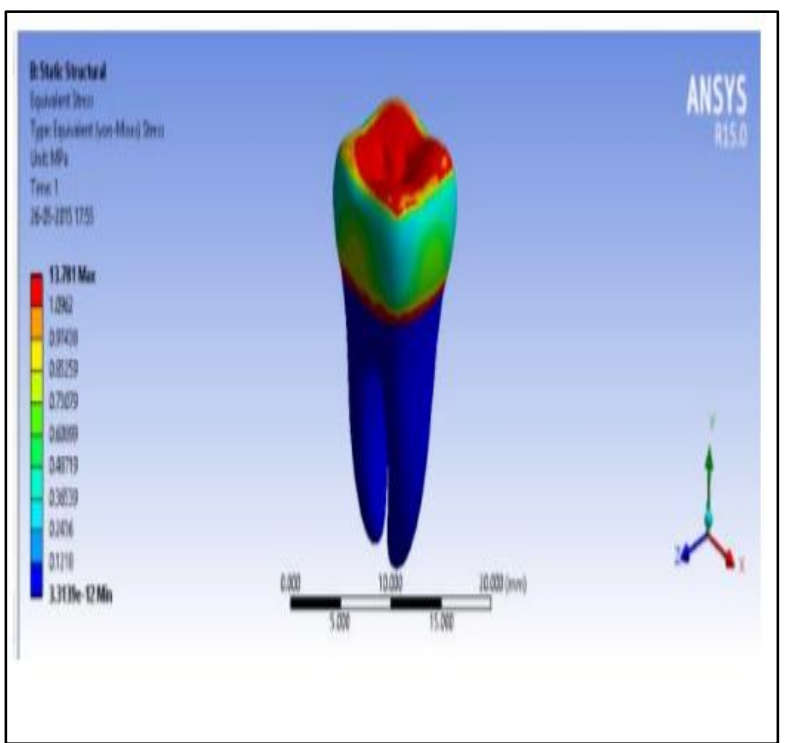

Figure 6. Stress examination for amalgam at $0^{0} \mathrm{C} \&$ $80 \mathrm{~N}$

Max Von- Mises stress; 13.7813 N/mm ${ }^{2}$

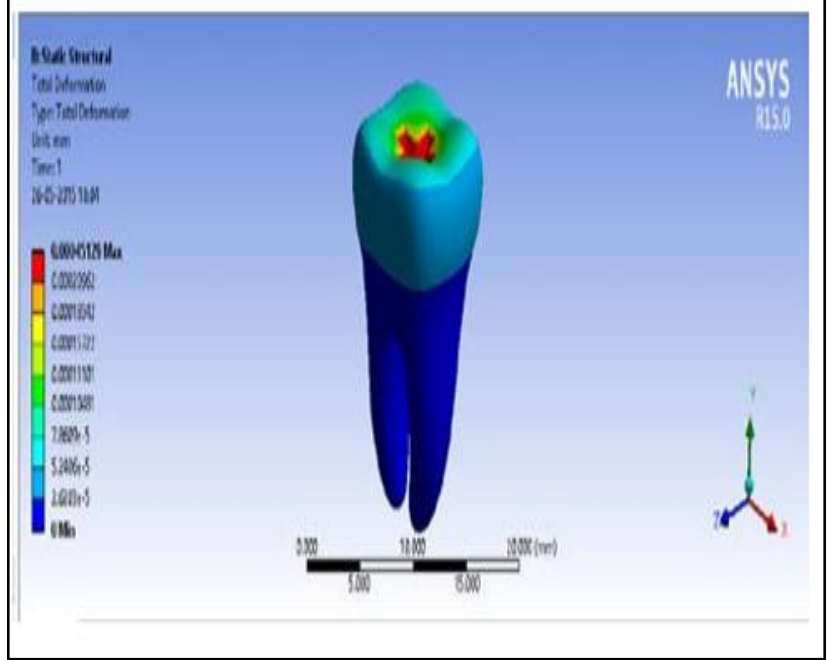

Figure 7. Distortion examination for

Composite/mixture at $0^{\mathbf{0}} \mathrm{C} \& 80 \mathrm{~N}$

Max Distortion; $0.0004513 \mathrm{~mm}$

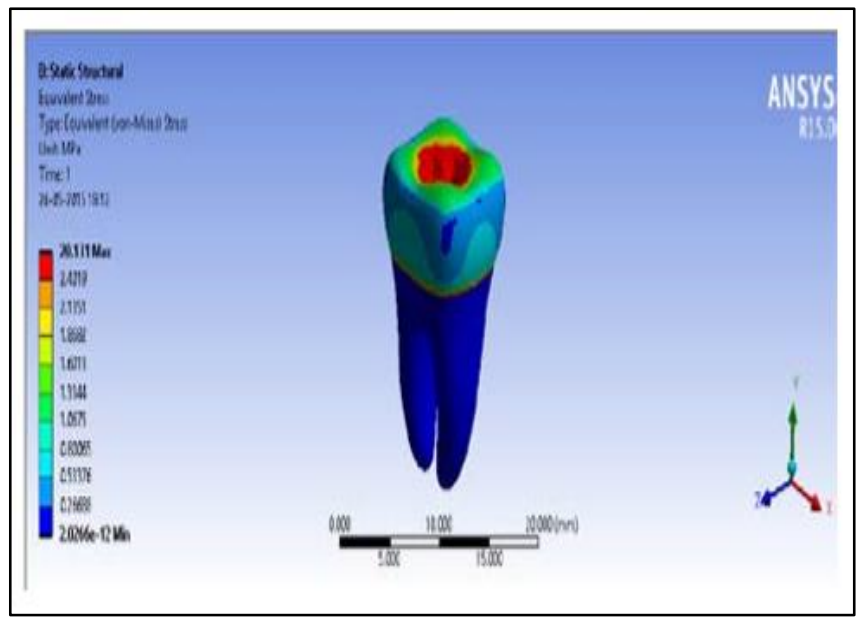

Figure 8. Stress examination for composite/mixture at $0^{0} \mathrm{C} \& \mathrm{80N}$

Max. Von- Mises stress; 20.1312N/mm²

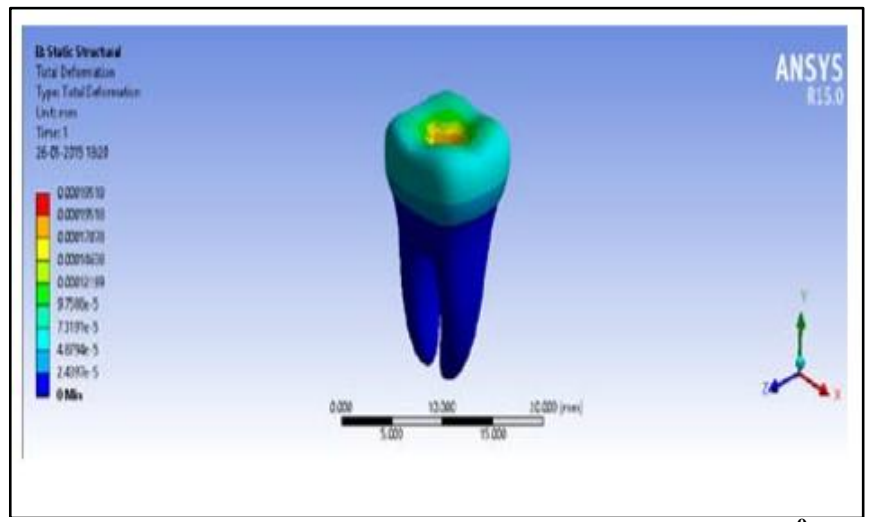

Figure 9. Distortion enquiry for Gold (Au) alloy at $0^{0}$ \& 80N

Max. Deformation; $0.0001952 \mathrm{~mm}$ 


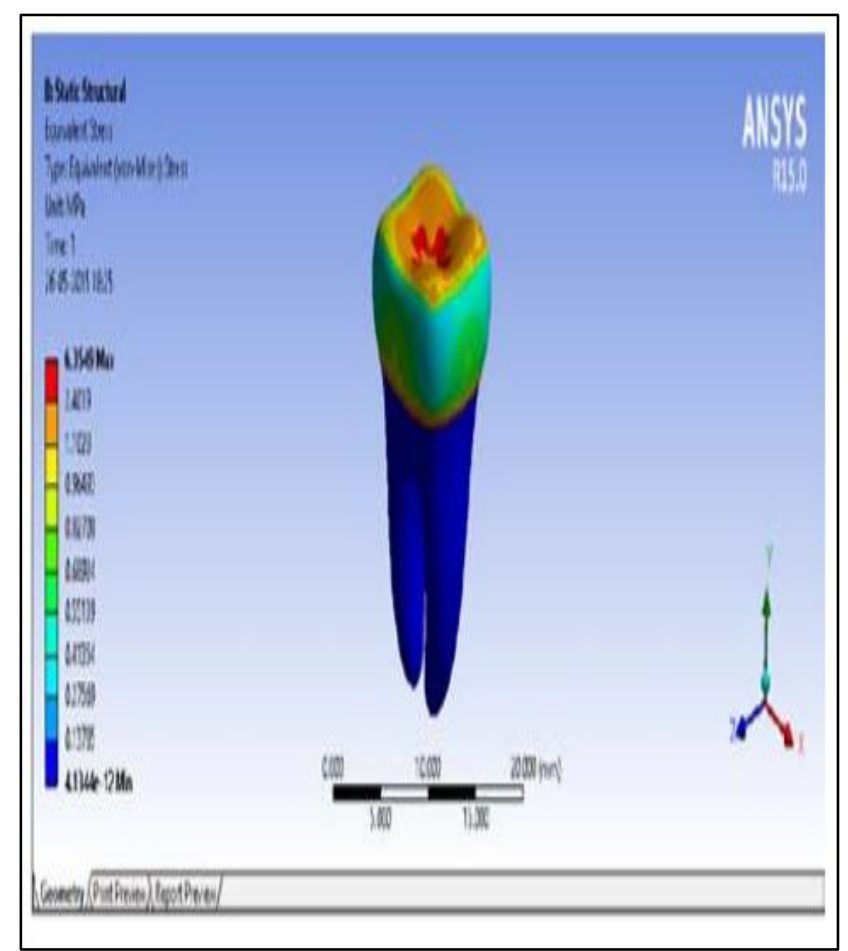

Figure 10. Stress inquiry for Gold (Au) alloy at $0^{0} \mathrm{C} \&$ $80 \mathrm{~N}$

Max. Von- Mises stress; $6.355 \mathrm{~N} / \mathbf{m m}^{2}$

The mechanical reactions ( $\max$ distortion \& Von-Mises stress) were recorded for each test compared to the temperature \& load for each/every material, employing QTIPLOT for 3-D view, and 3D surface resulting from the image is presented to section below.

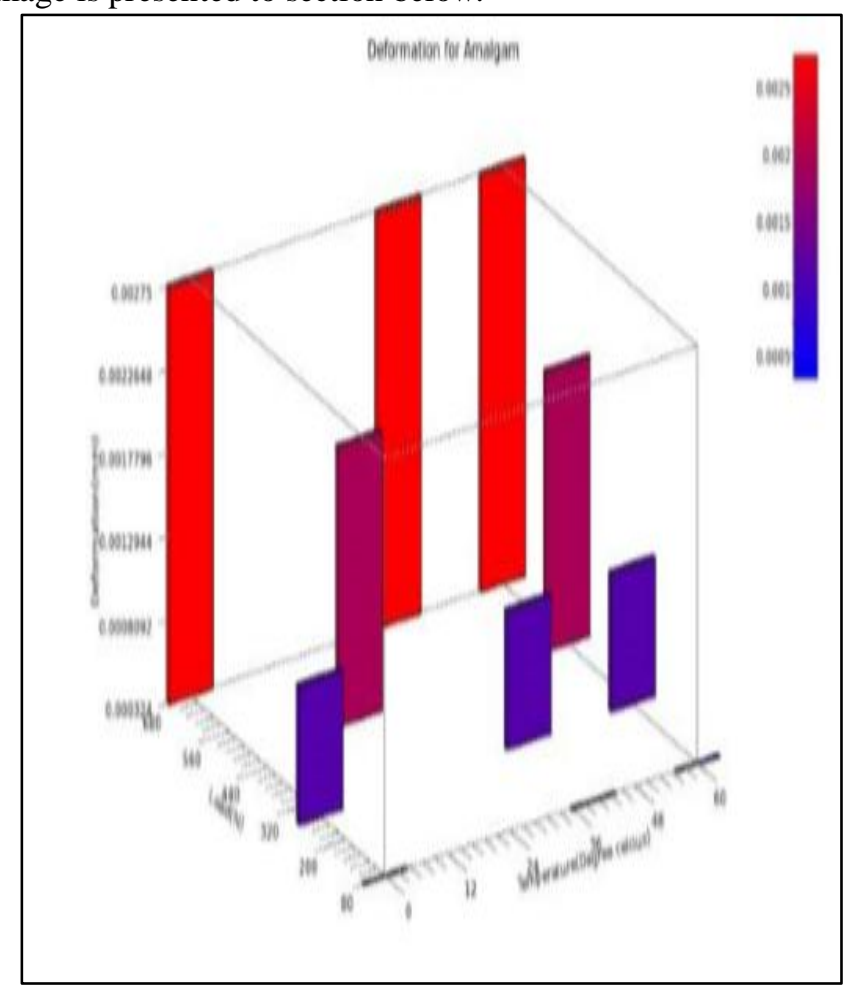

Figure 11. 3-D graph of Amalgam deformation

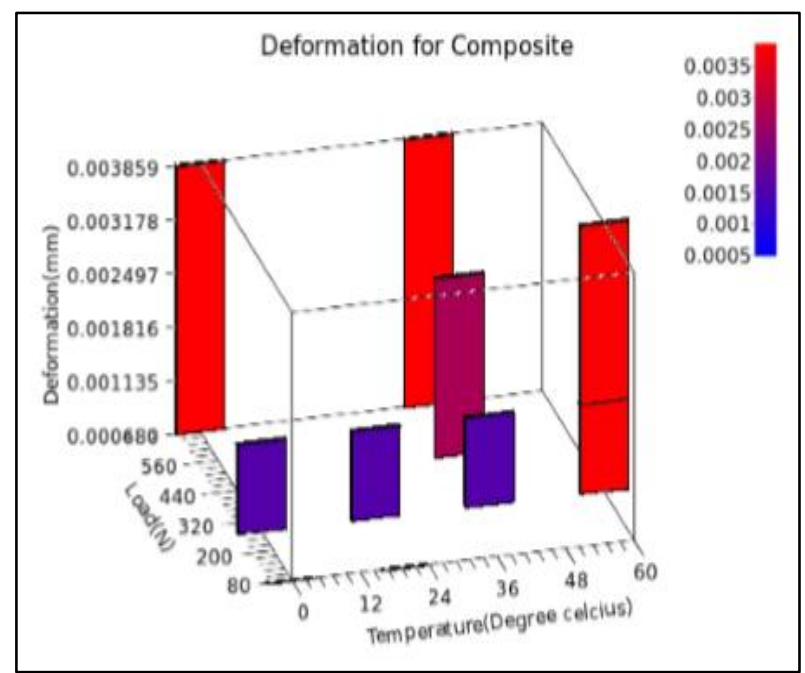

Figure 12. 3-D graph Composite deformation

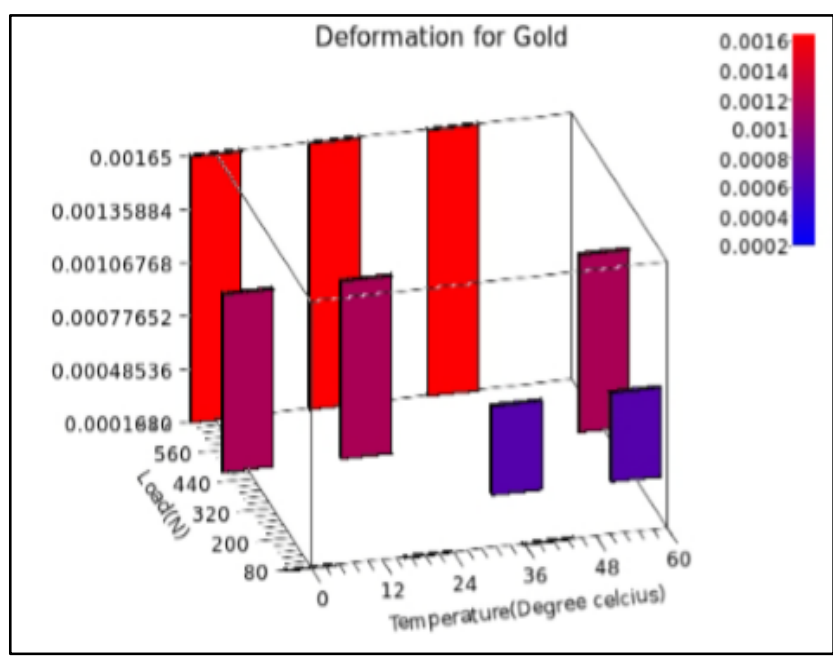

Figure 13. 3-D graph of Gold (Au) alloy distortion

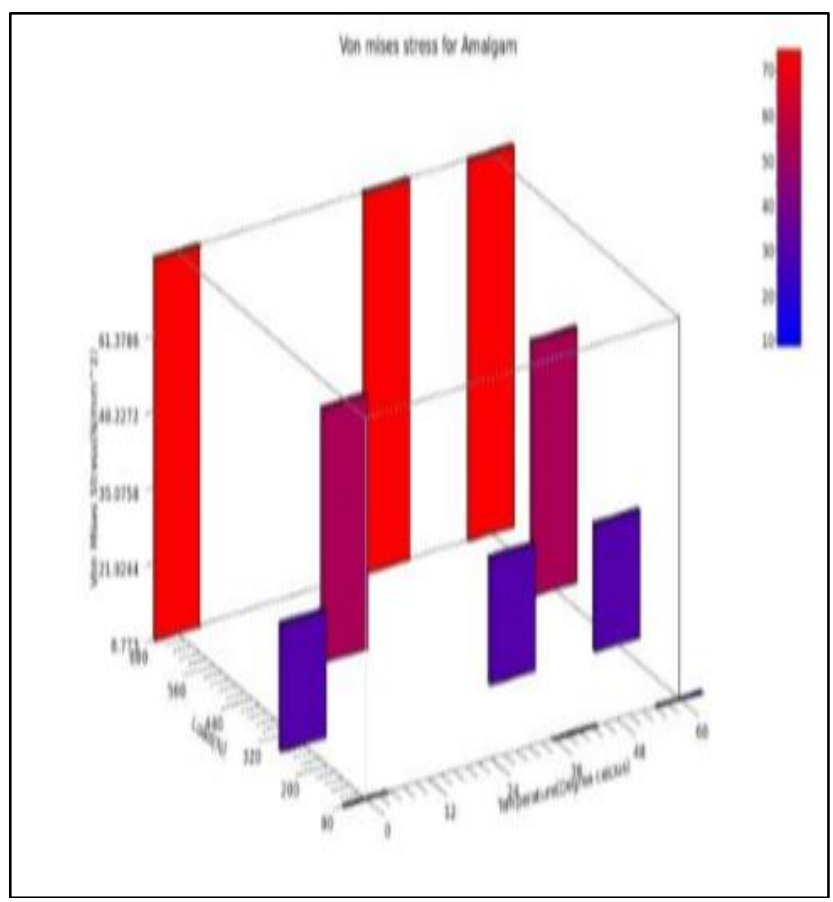

Figure 14. 3-D graph of Amalgam (Von-Misses) stress Blue Eyes Intelligence Engineering \& Sciences Publication 


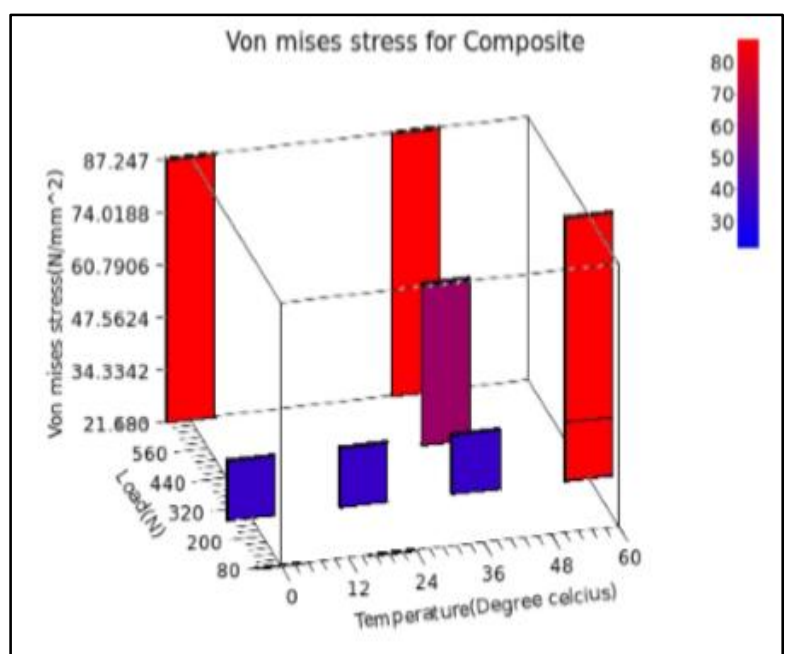

Figure 15. 3D graph of Von-Mises stress for Composite

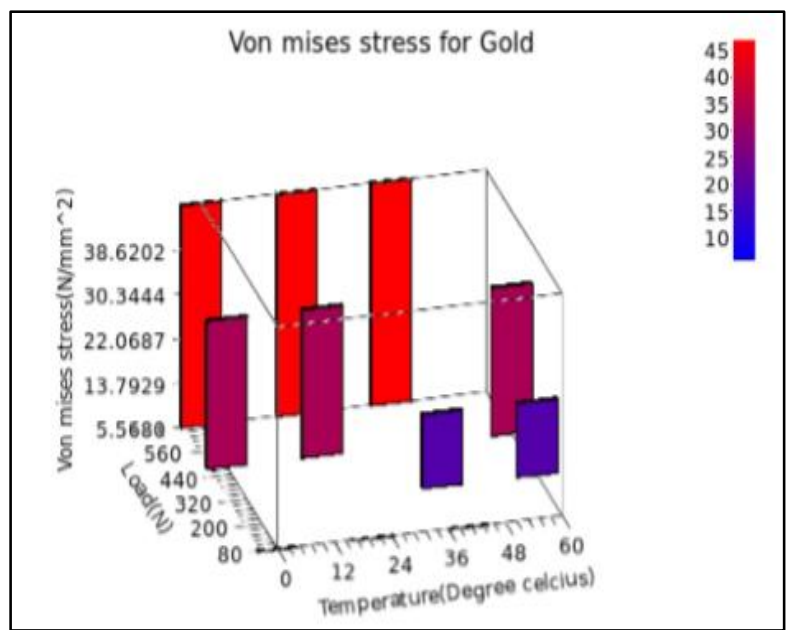

Figure 16. 3D graph of Von-Mises stress for Gold ally

\section{CONCLUSION AND DISCUSSION}

The results achieved as of ANSYS above disclosed that most significant surface change, the max deformation happened at the surface of occlusal, precisely on the filling material plus rises towards the other four surfaces (mesial, buccal, lingual and distal surfaces) and the roots, and the similar thing (Von Mises) stress was illustrated along the cervical line (a straight line between crown and roots) and spread to the crown \& its roots.

The result also shows that the rise in declining numbers and density increased on the rise in structural load but independently from the temperature lines (temperature from 0 to $60^{\circ} \mathrm{C}$ ) used in this work. The reason for not changing the temperature result is perhaps due to; the temperature range being considered $\left(0\right.$ to $\left.60^{\circ} \mathrm{C}\right)$ is much lower than the melting temperature for all the materials employed as filling material.

It is other than clear; the features of each engineering material are different with different temperatures, so in this work the features of the temperature of a room were selected for all particular items for each temperature set used in this work.

Additional, examination of the influence by using the QTIPLOT 3-D surface graph displays; the minimum values are associated with gold alloy, and the maximum deformation is recorded when composites were used. In addition, Gold $(\mathrm{Au})$ alloys \& composites/mixture materials have the $\min \& \max$ (von- Mises) stresses respectively. This can be because of the statement that, gold (Au) alloy has a close proximity with human Enamel \& Dentin in its mechanical characteristics.

\section{REFERENCES}

1. "Mandibular first molaraccess on 15/01/2015 Wikipedia." [Online]. Available: https://en.wikipedia.org/wiki/Mandibular_first_molaracc ess_on_15/01/2015. [Accessed: 18-Jul-2019].

2. Text Book of Endodontics - Kohli - Google Books." [Online]. Available: https://books.google.co.in/books?id=zwdyRs9HYpgC\&p $\mathrm{g}=\mathrm{PA} 130 \& \mathrm{lpg}=\mathrm{PA} 130 \& \mathrm{dq}=$ Mandibular+first+molaracce ss\&source $=$ bl\&ots $=e$ OQGjo5ay\&sig $=\mathrm{ACfU} 3 \mathrm{U} 2 \mathrm{rmcUw}$ GNJvF9pfQRpgVzQ_4c-

c7A\&hl=en\&sa $=X \& v e d=2 a h U K E w i t y N O K 2 r 3 j A h X N V$ 30KHfmUDP8Q6AEwG3oECAgQAQ\#v=onepage\&q= Mandibular fir. [Accessed: 18-Jul-2019].

3. L. R. American Association of Endodontists., R. E American Dental Association., and W. B. Case, Journal of endodontics., vol. 15, no. 7. [American Association of Endodontists].

4. S. Sharma, V. Kumar, and N. Kumar, "FEA approach of Dental restorative material under Structural and Thermal loads," 2016.

5. The Dental Material Commission-Care and Consideration."

6. A. Nyush, "Textbook of Dental Anatomy, Physiology and Occlusion, 1E (2014).pdf.".

7. M. Żenkiewicz and J. Richert, "Influence of polymer samples preparation procedure on their mechanical properties," 2008.

8. J. A. Helsen and Y. F. Missirlis, Biomaterials : a Tantalus experience. Springer, 2010.

9. S. Mulligan, G. Kakonyi, K. Moharamzadeh, S. F Thornton, and N. Martin, "The environmental impact of dental amalgam and resin-based composite materials."

10. M. Stanley J. Nelson, DDS, Wheeler's Dental Anatomy, Physiology and Occlusion. 2013.

11. S. Nelson, Wheeler's Dental Anatomy, Physiology, and Occlusion. 2013.

12. S. J. Nelson and M. M. Ash, "Orofacial Complex: Form and Function," in Wheeler's dental anatomy, physiology, and occlusion, 2010.

13. K. J. Anusavice, PHILLIPS. Ciencia de los materiales dentales. 2004.

14. E. Eliguzeloglu Dalkılıç, M. Kazak, D. Hisarbeyli, M. A. Fildisi, N. Donmez, and H. Deniz Arısu, "Can Fiber Application Affect the Fracture Strength of Endodontically Treated Teeth Restored with a Low Viscosity Bulk-Fill Composite?," Biomed Res. Int., vol. 2019, p. 3126931, 2019.

15. C. W. BARCLAY, D. SPENCE, and W. R. E. LAIRD, "Intra-oral temperatures during function," J. Oral Rehabil., vol. 32, no. 12, pp. 886-894, Dec. 2005 